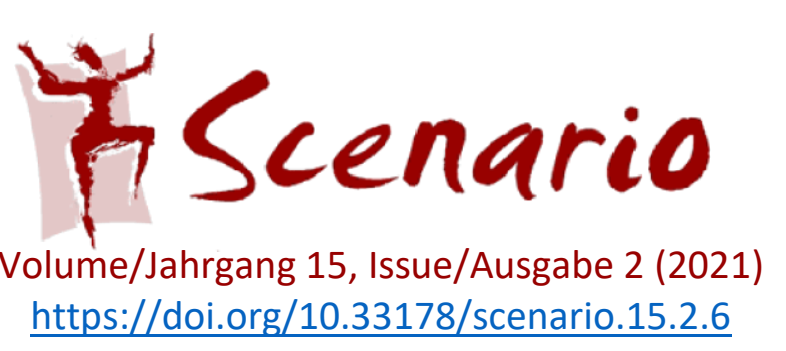

\title{
Whose act(ion)? Report on intercultural educators in critical conversation on ethical practice across disciplines
}

\author{
Anna Santucci, Kristin Johnson \& Donna Gamache-Griffiths
}

This piece introduces and recreates a critical dialogue which occurred in the summer of 2021 among educational practitioners at the University of Rhode Island (USA), during an interdisciplinary teach-in retreat on Intercultural Competence Development for Teachers and Learners. The authors were among the participants who collaborated on this project led by Anna Santucci; here, they offer a snapshot of the exchange that took place on the final day of the retreat. The themes that emerged throughout the teach-in, summarized in that closing conversation, significantly resonate with the RISE manifesto (Cañas, 2015). These themes include salient values, skills, and behaviors of interculturally competent educators and scholars whose understanding of ethical practice is grounded in empathy, and whose work strives to embrace radical creativity in envisioning possibilities for co-creation among all participants in the teaching and/or research experience - enacting education through and for "action" via human act-ivation and, therefore, act-ivism.

\section{Introduction}

How often do we pause to critically interrogate our daily practice as educators? The authors of this piece invite you to join their continuing conversation on ethical educational act(ion)s, which stemmed from an opportunity they had to gather shared reflection regarding intercultural competence in higher education.

The phrase "nothing about us without us" resonates for us, the authors, with the key ethical considerations we have been engaging with in our current work to further cross-disciplinary understanding and development of culturally aware teaching competencies at our institution.

Who is the "us"? What is lost and gained in determining an "us" in the ways it implies a "them"? How do we define those boundaries? When are we ethically compelled to do so in our teaching and research, so that we may explicitly define a system of oppression that we want to analyse? What are the ethical considerations raised by determining these categories in our analysis? Such are the theoretical challenges of defining cultures, languages, and groups in our scholarship and practice.

In the summer of 2021, the authors of this piece participated in a week-long retreat called Interdisciplinary Intercultural Competence Teach-in Retreat: Reflection, Growth, and Project 
Development. This event unfolded as a collaborative journey in which we engaged with and stretched ourselves around these questions, committing ourselves to embracing a process that entailed continual probing, rather than necessarily searching for final answers.

Anna Santucci (AS) convened this retreat as the kick-off event of a larger initiative on Intercultural Teaching \& Learning at the University of Rhode Island (URI). Many US Higher Education stakeholders have increasingly identified intercultural competence as a fundamental component in furthering our institutions' educational mission by nurturing the growth of our students, faculty, and staff as globally responsible citizens (Anderson et al., 2021; Murray, 2015). AS launched this initiative aiming to provide the University of Rhode Island (URI) with structured professional development opportunities designed and facilitated via interdisciplinary and integrated collaborations among critical partnering campus units, so that its educators may learn from each other's work, increase their sense of belonging to the institution's teaching and learning community, and progress on cross-departmental educational research and classroom projects. Among the tangible outcomes of the kick-off retreat was a proposal for a High Impact Teaching seminar open to all URI instructors, to be offered by AS and based on her Office for the Advancement of Teaching and Learning's existing professional development model: the seminar will target the development of URI instructors' knowledge, skills, behaviors, attitudes, and values as interculturally competent educators (curiosity, humility, flexibility, empathy, non-judgmentalness), enhance their ability to apply these elements in their teaching practice, and increase their confidence in designing course assessments and activities that help students grow as culturally responsible citizens (and, thus, meet institutional general education learning outcomes in the areas of global, diversity and civic responsibilities).

All team members AS identified for this retreat were invited to contribute as critical partners in its realization, including co-authors Kristin Johnson (KJ) and Donna Gamache-Griffiths (DG). The retreat's curriculum was built collaboratively, and each participant led a portion of the week's workshops: they provided an overview of influential theories and frameworks for their scholarship and practice, shared practical examples from their classroom and/or research, and facilitated experiential activities for the group to apply these concepts. General prompts AS circulated in preparation were:

- What does Intercultural Competence mean in my field, and why does it matter for graduates in my program?

- How do I define the knowledge, skills, values, and attitudes related to intercultural growth in my scholarship and educational practice? 
- How do/might I assess my students' development in these learning areas? How do I facilitate scaffolded experiences for them to meet these goals?

- What are my own venues for intercultural professional development?

- Where do Intercultural Competence and JEDI (Justice, Equity, Diversity, and Inclusion) meet?

On the last day, participants shared key takeaways, discussed commonalities and differences across the presented models and perspectives, and determined the next steps for possible projects. That last day of the retreat's agenda was intentionally left unscripted to allow for the co-creation of knowledge emerging throughout the week from each participant's sharing of their experience and perspective. This piece captures and expands on reflections from that final day, in which we collectively explored positionality, agency, and power in ethically performing our practice as critically reflective higher education instructors across various disciplines.

Represented disciplines and stakeholders included Educational Development, Scholarship of Teaching and Learning, Performative Intercultural Education, Political Science/International Relations \& Diplomacy, Business/Innovation and Entrepreneurship, TESOL/Bilingual Education, World Languages, Global Initiatives, Engineering, General Education and Community, Equity and Diversity Leadership. The retreat was intentionally designed to bring to the forefront fundamentally needed interdisciplinary perspectives as we explored the concept of culture, which allowed us to pay more intentional attention to the variety of disciplinary and identity-related languages we each speak. Making meaning together through those diverse languages increased our awareness of the multiplying and constantly evolving ways in which power determines the boundaries of our in-groups and out-groups (to use the terminology employed by social psychologists to describe our implicit ways of determining who we identify and feel affinity with, and around whom we feel we belong), as we explore and stretch our conceptualization of JEDI.

In opening that final retreat day, AS offered a summary of common threads emerging in the practice of all participants throughout the week. She proposed empathy as our key common guiding ethical principle. We pondered and searched for helpful definitions. One of us shared Agar's interpretation of Stein's work on empathy as the basis for the intersubjective pursuit of knowledge in human social science, throwing us a lifeline: "How, then, can a human person have a truly empathetic encounter? The answer lies in de-centering the self through a transcendent exercise of the free will. [...] To avoid assimilation and suppression when encountering another, the human person has to stop using themself as the standard of reality" (Agar 2021, p. 130). Yet how might we actually strive to stop using ourselves as the standard 
of reality? Challenging ourselves to think through that in our praxis as researchers, Agar offers that 'A connection must be worked out, a translation, an encounter with the 'foreign'. The rational reconstruction includes the beliefs, desires, and purposes of both research subjects and the researcher" (Agar 2021, p. 131). Agar is specifically referring here to the human "subjects" of social science; this conceptualization of an intersubjective space can helpfully accompany all of us who work in interaction with meaningful human encounters in our scholarly and teaching practice: "The [practice] is intersubjective [...] - based on what happens between subjects, neither objective nor subjective, in any simple way. (Agar 2021, p. 131; [practice] is "science" in original).

During that closing day, AS noted how the tenets around which we were trying to define these fundamentally empathetic encounters resonated strikingly with those expressed in the RISE manifesto. We offer them here for Scenario readers as an invitation to join us as we continue to reflect on our practice, and yet step into it every day striving for humility and generosity:

1) in our professional development and learning, the active process of educating ourselves and each other as educators;

2) within our classrooms, promoting our vision of interculturally competent curricula in design and execution;

3) in our scholarship, approaching our disciplines with a call for beginning points of inquiry to acknowledge and reform existing hegemonic colonial frames.

Framing our understanding of the educator as a practitioner/artist as addressed in the RISE manifesto, we highlight four tenets that can guide our ethical pedagogical practice in creating and facilitating educational spaces; their links to the manifesto are marked by slightly rephrasing its points. We hope this adapting/adopting of the manifesto around these four key areas may be a helpful tool for other educational practitioners as it continues to be for us.

\section{Who is benefiting from the knowledge/learning created in the educational encounter/intervention/happening?}

RISE 1: Process not product

As educators, we may be talented at our craft or in our discipline/field, but we cannot assume that this automatically translates into an ethical, responsible, and self-determining process. Understanding the need to create a community of trust in an educational setting via mutual commitment to cultural development also implies understanding that it is never a fool-proof methodology. 
RISE 2: Always critically interrogate our intentions

Subjecting our intentions to critical, reflexive analysis requires a significant level of selfawareness, which we too rarely exercise. What is our motivation to teach or work with a given specific subject matter and a specific set of learners? Why at this specific time? Which people and institutions are benefiting from the exchange?

3 Who has agency and voice? Who owns the process? Who determines its design and the dynamics of its unfolding?

RISE 3: Each must realise our privilege

What biases do we all inevitably carry with us? What is the impact of our identities, even when we approach the other with what we consider good intentions? What socio-economic positionality and power dynamics inform and shape any educational setting? Knowing how much space we take up and when to step back is a never-ending journey of learning.

RISE 4: Participation is not always progressive or empowering

Any course or project may have elements of participation, but are we aware of how this may be limiting, tokenistic or condescending? Our demands on any community's sharing of stories may just as easily be disempowering. What frameworks do we inevitably impose on others' participation in any experience of our own design, even before meeting them? What power dynamics are we reinforcing with such frameworks? What relationships are we creating or reinforcing (e.g., informant vs. expert, enunciated vs. enunciator)?

\section{Who has a choice in initiating the encounter/intervention/happening? Who is shaping the narrative?}

\section{RISE 5: Presentation vs representation}

Do we know the difference? What and who is presented in our scholarship and practice? Are our students and the populations served by our research represented?

RISE 7: Do not expect others to be grateful

No community is waiting for our acknowledgment of their struggle through our art/craft/teaching practice. Moreover, the dividing line between who is giving and who is receiving in the exchange is much blurrier than we are generally willing to acknowledge.

RISE 8: Do not reduce others to an issue 
People are wonderfully complex and have varied experiences, knowledge, and skills. The other we encounter, be it a student or community member, can speak of many things; our work should strive to never reduce anyone to one narrative.

\section{Practice is NEVER neutral}

RISE 10: Art is not neutral

Whether or not a community has been politicized in practical/institutional/partisan terms, how do we yield our power responsibly in the always-already-political educational environment?

We hope the reader will enjoy listening to this recorded ${ }^{1}$ Zoom conversation among the authors, in which we tried to recreate, and further reflect upon, the powerful exchange of ideas that was generated during our retreat around its connections with the points raised in the RISE manifesto.

During our retreat, it was eye-opening to witness our collective returning, again and again, from so many angles and both teaching and scholarship perspectives, to these key common threads around ethical practice grounded in empathy and authentic dialogue. We kept expressing our heartfelt need to critically investigate whose stories are told and how; we were not able let go of that urge for a constant further questioning of the ways we do what we do. Preparing to lead the retreat's closing session, AS pinpointed the key threads running through the retreat, such as the following: "Do no harm - not more benefit for us than for the population we are serving". KJ and DG, as well as other participants, had touched upon this concern in their presentations: how do the ways in which we define "expertise" and produce "knowledge" in our disciplines, and indeed within the US Higher Education system, hold up to this standard, to the moral imperative of benefiting not (just) ourselves but the populations we serve?

The RISE manifesto's 10 points emerged as a path that could help us make sense of our shared hopes and intentionality in this regard, speaking to each of us as critically reflective practitioners across disciplines, artists in our craft as educators and scholars. As we opened up our practice for critical interrogation and explored its intentionality (RISE manifesto, 2), we collectively found ourselves joined in the desire to resist any productive finality and allow ourselves and our students to engage in a constant process (RISE manifesto, 1) of "active learning." The learning processes we envisioned go beyond that buzzword commonly used in our institutions; they posit radical creativity in their envisioning of possibilities for co-creation

\footnotetext{
${ }^{1}$ https://youtube.com/playlist?list=PL tFOILtYTtcxdvbzVgwjQeZ9xHV4c8ZB
} 
among all participants in the learning experience or research project; they constitute a fuller, more profound sense of the word "active". In a phrase AS coined, "they enact education through and for action, via human act-ivation and therefore act-ivism".

As we shared our stories, we each brought to the table mentors and thinkers that have helped us and continue to contribute to our scholarship and practice along the journey, such as Paulo Freire (1968), Augusto Boal (1979), Michael Byram (2008). A common thread among all of them, across the various disciplines represented in our retreat, was being in harmony with practitioners that never shied away from political responsibility and were active policymakers - practice is NEVER neutral (RISE manifesto, 10). We teach people, and people are our polis. Education is a quintessentially and intrinsically cultural phenomenon. The importance of a non-static understanding of "culture" as a verb rather than a noun repeatedly recurs in our explorative conversations. As we act, intervene, research, publish, communicate, teach, and learn, we encounter the other: the intercultural communicative competence frameworks shared during the retreat reminded us of how hard it is to do so effectively and appropriately (Fantini, 2009). We allowed ourselves to ask each other, genuinely: if what is effective and appropriate is inextricably culturally bound, is the logical and ethical conclusion, then, complete moral relativism? Where is that line? Who ought to draw it other than each of us individually?

Readers might relate to the experience of treasuring those rare moments in which we find ourselves part of a community within which we somehow feel we belong enough, acceptably in alignment with each other's values, acceptably in agreement - at least for a few fleeting moments - on the whereabouts of that line. The retreat we have discussed here was one of those moments. Yet even when we find those infinitely precious spaces, and perhaps especially then, as they are the ones that constitute the most fertile (and safe?) terrain for further stretching, our questioning minds and hearts cannot yield and accept good enough answers. Is there such a thing as a purely selfless act? In any pursuit of justice, who is shaping and owning the narrative? (RISE manifesto, $7 \& 8$ ) Who is the actor, the subject holding power and agency? (RISE manifesto, 3 \& 4) Is there such a thing as ethical intellectual exploration, and intervention?

Coming back to that fundamental engagement with empathy as our guiding force, we worked towards possible answers to the following questions: Are we achieving that intersubjective space posited by Agar in our daily practice? Is regularly reminding ourselves of such questions enough? Yet we continue to embrace the struggle as we constantly experience the tension between theory and practice; we move on trying to accept the fascinating impossibility of balancing theory, so wonderfully utopian, and practice, in some ways so limited and yet necessary in our daily work, as we act for justice within each of our spheres of influence. 
Santucci, Johnson \& Gamache-Griffiths: Whose act(ion)?

Resisting final answers as our ethical tenet, our invitation is to continue asking the questions that matter - together.

Bibliography

Acharya, A (2014). Rethinking power, institutions and ideas in world politics: Whose IR? Routledge. https://doi.org/10.4324/9781315885346

Acharya, A (2016). Advancing global IR: challenges, contentions, and contributions. International Studies Review 18(1): 4-15. https://doi.org/10.1093/isr/viv016

Agar, M. (2021). The lively science: Remodeling human social research. Routledge Taylor \& Francis Group. https://doi.org/10.4324/9781003052395

Anderson, K. D., Jackson, M., \& Trogden, B. (2021). Looking back, moving forward: Intercultural communication must be part of all Learning. AAC\&U Liberal Education 107(1).

https://www.aacu.org/article/looking-back-moving-forward

Bennett, M.J. (1986). A developmental approach to training for intercultural sensitivity. International journal of intercultural relations 10(2), 179-196. https://doi.org/10.1016/0147-1767(86)90005-2

Bennett, M. (2017). Developmental model of intercultural sensitivity. In Y. Kim (Ed), Encyclopedia of intercultural communication. Wiley. https://doi.org/10.1002/9781118783665.ieicc0182

Boal, A. (1998). Legislative theatre: Using performance to make politics. Routledge.

Boal, A. (1979). Theater of the oppressed (Charles A. and Maria-Odilia Leal McBride Trans.). Urizen Books.

Buzan, B (2016). Could IR be different? International Studies Review 18(1), 155-157.

\section{https://doi.org/10.1093/isr/viv025}

Byram, M. (2008). From foreign language education to education for intercultural citizenship: Essays and reflections. Multilingual Matters Ltd. https://doi.org/10.21832/9781847690807

Byram, M. (1997). Teaching and assessing intercultural communicative competence. Multilingual Matters.

Cañas, T. (2015). 10 things you need to consider if you are an artist. http://riserefugee.org/10-thingsyou-need-to-consider-if-you-are-an-artist-not-of-the-refugee-and-asylum-seeker-communitylooking-to-work-with-our-community/

Deardorff, D. K. (Ed.) (2009). The Sage handbook of intercultural competence. Sage Publications.

Dolan, J. (2005). Utopia in performance: Finding hope at the theater. University of Michigan Press. https://doi.org/10.3998/mpub.119520

Eun, Y.-S. (2019). An intellectual confession from a member of the " non-white" IR community: a friendly reply to David Lake's "White 'Man's IR." PS: Political Science \& Politics 52(1), 78-84. https://doi.org/10.1017/S1049096518001208 
Santucci, Johnson \& Gamache-Griffiths: Whose act(ion)?

Fantini, A.E. (2009). Assessing Intercultural Competence. In D. Deardroff (Ed.), The Sage Handbook of Intercultural Competence (pp. 456-475). Sage Publications.

Freire, P. (1968/2003). Pedagogy of the oppressed. Continuum.

Lake, D. (2016). White Man's IR: An Intellectual Confession. Perspectives on Politics 14(4), 1112-1122. https://doi.org/10.1017/S153759271600308X

Maclntyre, A. C. (1981). After virtue: A study in moral theory. Duckworth.

Murray, C. (2020). Imperial dialectics and epistemic mapping: From decolonization to antiEurocentric IR. European Journal of International Relations 26(2), 419-442. https://doi.org/10.1177/1354066119873030

Santucci, A. (2019) Performing language and culture: Teaching and learning Italian through critical embodied encounters. [Doctoral dissertation, Brown University]. Brown Repository.

Verschelden, C. (2017). Bandwidth recovery: Helping students reclaim cognitive resources lost to poverty, racism, and social marginalization. Stylus. 